\title{
Research Article \\ Effect of Dual Fuel Nozzle Structures on Combustion Flow Field in CRGT Combustor
}

\author{
Hongtao Zheng, Gang Pan, Xi Chen, and Xiaoming Hu \\ College of Power and Energy Engineering, Harbin Engineering University, Harbin, Heilongjiang 150001, China \\ Correspondence should be addressed to Hongtao Zheng; zhenghongtao9000@163.com
}

Received 9 May 2013; Revised 30 September 2013; Accepted 30 September 2013

Academic Editor: Oleg V. Gendelman

Copyright (c) 2013 Hongtao Zheng et al. This is an open access article distributed under the Creative Commons Attribution License, which permits unrestricted use, distribution, and reproduction in any medium, provided the original work is properly cited.

\begin{abstract}
Three different structures of a new dual fuel nozzle design concept (inner swirl nozzle, double swirl nozzle, and outer swirl nozzle) were developed for the chemically recuperated gas turbine (CRGT) combustor. The combustion flow fields in the combustor with the three nozzles were investigated, respectively, based on the FLUENT simulation. The realizable $k-\varepsilon$ model and PDF model were adopted, respectively, for the turbulence flow and nonpremixed reformed gas combustion. The obtained results using these models showed good agreement with experimental results in original oil combustor. The effects of different dual fuel nozzle structures on the flow field, fuel concentration distribution, and temperature distribution in the combustor were simulated and analyzed. Results suggest that the double swirl nozzle and outer swirl nozzle can form a better flow field with obvious central recirculation zone (CRZ), shorten fuel and air mixing distance, and obtain a more uniform outlet temperature distribution, in comparison with the inner swirl nozzle. However, compared with double swirl nozzle, the outer swirl nozzle can result in a better combustion flow field with the high temperature region in the CRZ, which is important to stabilize the flame.
\end{abstract}

\section{Introduction}

Since gas turbine is compact, lightweight, quick starting, highly reliable, and simple to operate, it has been used widely for many years in aviation, shipping, electric power, fossil oil, and other industrial fields [1]. However, certain problems have been identified under practical operating conditions, namely, low thermal efficiency of the system and high emission including $\mathrm{NO}_{X}[2]$. In order to solve these problems, the CRGT system is proposed [3]. In the CRGT system, gas turbine is started with the oil fuel. When the system runs stably, the mixture of oil and steam in the reformer is heated by the gas turbine flue gas, and an endothermic reaction occurs between the oil and the steam. The reaction results in the production of reformed gas which includes plenty of steam and hydrogen. The reformed gas is then fed into the turbine combustor. At the same time, the flow rate of oil fuel fed into the combustor is reduced gradually until the oil fuel is replaced by the reformed gas. Obviously, the combustor for the CRGT system should be able to burn the gas and oil dual fuels. Therefore, it is important to design a suitable dual fuel combustor for this system, especially a dual fuel nozzle.
Fuel nozzle is a key component of the combustor. Lots of researches on the fuel nozzle have been carried out through experiments. Terasaki and Hayashi [4] developed a double swirler burner. The emission characteristic of the burner was compared with those for the swirl burners of conventional configurations. The test results showed that the double swirler burner could achieve better fuel-air mixing and the lowest $\mathrm{NO}_{X}$ emissions level. Iyogun et al. [5] investigated the impact of nozzle geometry on swirling flame stability. They found that the nonaxisymmetric fuel nozzle increased the size and dynamics of the flow recirculation zones and induced higher levels of turbulence intensities when compared with axisymmetric fuel nozzle. Li et al. [6] found that the heat transfer and $\mathrm{CO}$ emission of impinging premixed flames were affected by the nozzle diameter and nozzle arrangement. Zhen et al. [7] performed an experiment study to investigate the effects of the nozzle length on the emission of a burner utilizing a multi-fuel-jet inverse diffusion flame. They found that the flame centerline temperature and $\mathrm{CO} / \mathrm{CO}_{2}$ concentrations were significantly affected by the nozzle length. Lee and Yoon [8] developed a gas turbine fuel nozzle for dimethyl ether. The performance of the newly developed nozzle was verified 
through a comparison with the original nozzle. The newly nozzle could prevent the flashback and reduce emissions of $\mathrm{NO}_{X}$ and CO. Mansour et al. [9] designed a highly stabilized concentric flow conical nozzle burner. The flow filed, temperature, and $\mathrm{OH}$ radical outside the cone were measured. They found that the flame of this burner had a better stabilization performance than the similar flames without cone. Koyama and Tachibana [10] designed a low-swirl burner for the liquidfuel. The effects of nozzle tip shape on flow patterns were investigated through experiment. They found that chamfer dimensions primarily affected the axial position of the flame. However, there is little published data on the dual fuel nozzle design for the CRGT system.

On the other hand, the fast development of computer and methodology of numerical computation technology have enabled computational fluid dynamics (CFD) to play a great role in combustor design. Using CFD technology lowers experimental costs and provides guidance in the optimal design of the structure. Many scholars used the CFD to get information on the flow field of combustor. Liedtke and Schulz [11] designed a new lean burning combustor. They got an insight into the flow structures and information on the location of the pilot and main flame within the combustor by the commercial code CFD-ACE. Chui et al. [12] evaluated burner and combustor design concepts using CFD. They found that the CFD could be an efficient tool for evaluating such burner and combustor design. Koyama and Fujiwara [13] used CFD to predict the gas fuel concentration in the combustor with three gas swirl injection methods. They found that reverse swirl injection could result in good fuel-air mixing and stable flame. Al-attab and Zainal [14] used FLUENT to determine the optimum design of the pressurized cyclone combustor. Finally, the combustor height, diameter and outlet geometry were determined. Arghode and Gupta [15] calculated the combustor flow field with FLUENT, and discussed the effects of air and fuel injection diameter and confinement size on gas recirculation and fuel/air mixing characteristics. Xing et al. [16] investigated the effects of various height-to-length ratios of the cavity on the flow structure in the trapped vortex combustor through CFD method.

In this study, in order to burn the reformed gas effectively, three different structures of a new dual fuel nozzle design concept were developed. The FLUENT was used to analyze the nozzles for the CRGT combustor. The effects of different dual fuel nozzle structures on the flow field, fuel concentration distribution, and temperature distribution in the combustor were discussed. This work could help improve the design of the dual fuel nozzle for the CRGT combustor and save experiment cost.

\section{Geometry and Mathematical Model}

2.1. Geometry. The gas turbine combustor is designed to burn the fuel efficiently. The basic geometry of the combustor is shown in Figure 1. The size of the combustor is $391 \mathrm{~mm}$ in the $Z$ direction, $245 \mathrm{~mm}$ in the $Y$ direction, and $743 \mathrm{~mm}$ in the $X$ direction. In this paper, three different dual fuel nozzle structures (inner swirl nozzle, outer swirl nozzle, and double swirl nozzle) were developed, as shown in Figure 2. A hybrid mesh

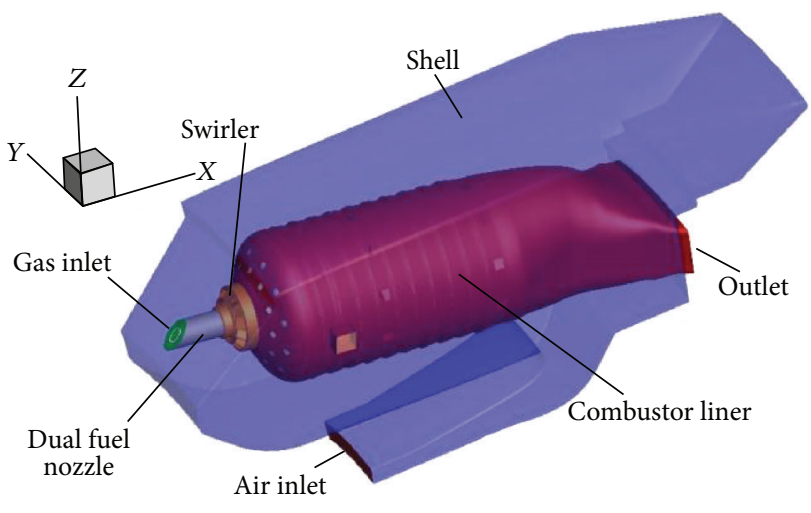

FIGURE 1: Geometry structure of combustor.

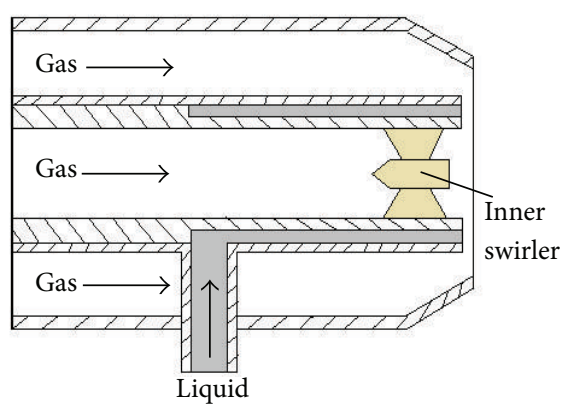

(a) Inner swirl nozzle

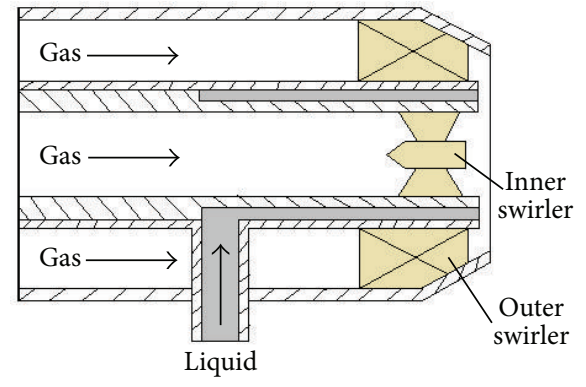

(b) Double swirl nozzle

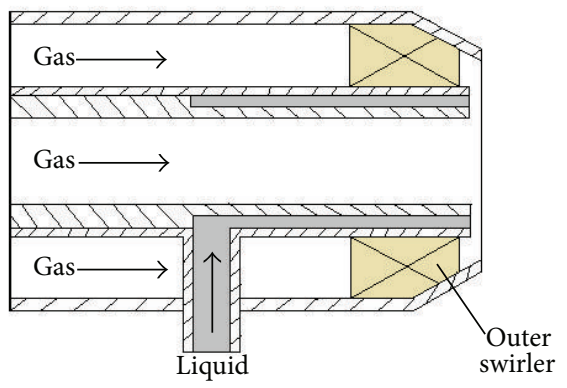

(c) Outer swirl nozzle

FIGURE 2: Geometry structures of the dual fuel nozzles.

was generated for the combustor, as shown in Figure 3. And the total grid number is $3,500,000$.

Boundary conditions are as follows: reformed gas inlet temperature is $723 \mathrm{~K}$, inlet flow rate is $0.3 \mathrm{~kg} / \mathrm{s}$, and the composition of reformed gas is shown in Table 1. Air inlet 


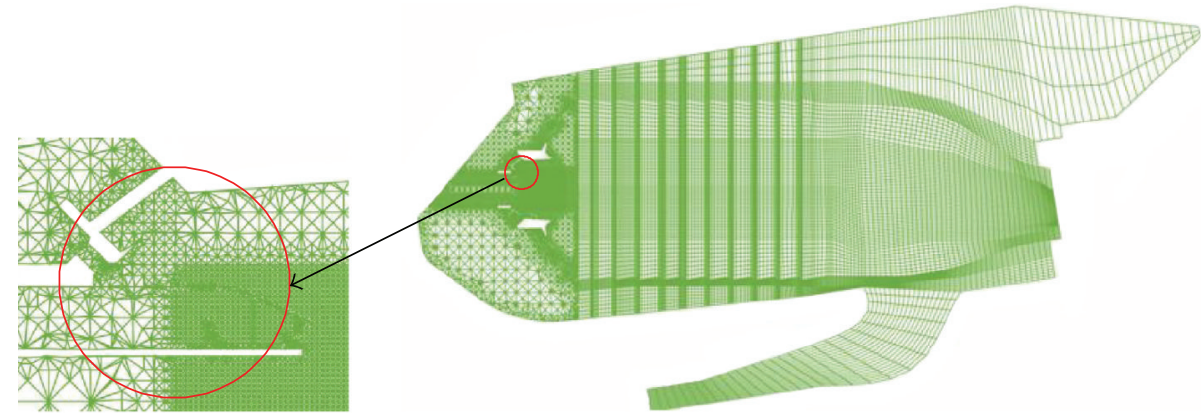

Figure 3: Hybrid mesh for combustor.

TABLE 1: Composition of reformed gas.

\begin{tabular}{lcccc}
\hline Constituents & $\mathrm{CO}$ & $\mathrm{CO}_{2}$ & $\mathrm{H}_{2}$ & $\mathrm{H}_{2} \mathrm{O}$ \\
\hline Mole fraction & 0.0561 & 0.09979 & 0.40208 & 0.44203 \\
\hline
\end{tabular}

temperature is $670 \mathrm{~K}$, inlet flow rate is $2.7 \mathrm{~kg} / \mathrm{s}$, and inlet pressure is $1.01325 \mathrm{MPa}$.

Outlet: pressure outlet.

Wall: adiabatic boundary.

2.2. Mathematical Model. The mathematical equations describing the reformed gas fuel combustion are based on the equations of conservation of mass, momentum, energy, and species transport together with other supplementary equations for the turbulence and combustion. The realizable $k-\varepsilon$ model [17] was adopted to simulate the turbulence flow. The equations for the turbulent kinetic energy $k$ and the dissipation rate $\varepsilon$ of the turbulent kinetic energy were solved. For nonpremixed reformed gas combustion, the PDF model [18] was used. The equations are as follows (ignore radiation and gravitation) [19]:

Continuity Equation

$$
\nabla \cdot(\rho \vec{V})=0
$$

Momentum Conservation Equation

$$
\nabla \cdot(\rho \overrightarrow{V V})=-\nabla p+\nabla \cdot \tau
$$

where $\tau$ is the stress tensor,

Energy Conservation Equation

$$
\nabla \cdot(\rho \vec{V} E)=\nabla \cdot\left(k_{\mathrm{eff}} \nabla T-p \vec{V}+\tau \cdot \vec{V}-\sum_{i=1}^{N_{s}} h_{i} \overrightarrow{J_{i}}\right)+S_{h}
$$

where $k_{\text {eff }}$ is the effective conductivity, $\vec{J}_{i}$ is the diffusion flux of species $i$, and $S_{h}$ is the heat of chemical reaction,

Species Transport Equation

$$
\nabla \cdot\left(\rho \vec{V} m_{i}\right)=-\nabla \cdot \overrightarrow{J_{i}}+R_{i}
$$

where $R_{i}$ is the net rate of production of species $i$ by chemical reaction,
State Equation

$$
p=\sum_{j=1}^{N_{s}} \frac{\rho m_{j} R T}{M_{j}}
$$

Realizable $k-\varepsilon$ model

$$
\begin{aligned}
\nabla \cdot(\rho \vec{V} k)= & \nabla \cdot\left(\Gamma_{k} \nabla k\right)+G_{k}+G_{b}-\rho \varepsilon-Y_{k}+S_{k}, \\
\nabla \cdot(\rho \vec{V} \varepsilon)= & \nabla \cdot\left(\Gamma_{\varepsilon} \nabla \varepsilon\right)+\rho C_{1} S \varepsilon \\
& \quad \rho C_{2} \frac{\varepsilon^{2}}{k+\sqrt{\nu \varepsilon}}+C_{1 \varepsilon} \frac{\varepsilon}{k} C_{3 \varepsilon} G_{b}+S_{\varepsilon}
\end{aligned}
$$

where $G_{k}$ represents the generation of turbulence kinetic energy due to the mean velocity gradients, $G_{b}$ is the generation of turbulence kinetic energy due to buoyancy, $Y_{k}$ represents the contribution of the fluctuating dilatation in compressible turbulence to the overall dissipation rate, $S_{k}$ and $S_{\varepsilon}$ are userdefined source terms, $C_{1 \varepsilon}=1.44, C_{2}=1.9, \sigma_{k}=1.0$, and $\sigma_{\varepsilon}=$ 1.2 ,

PDF Combustion Model

$$
\begin{gathered}
\nabla \cdot(\rho \vec{V} \bar{f})=\nabla \cdot\left(\frac{\mu_{t}}{\sigma_{t}} \nabla \bar{f}\right)+S_{\text {user }}, \\
\nabla \cdot\left(\rho \vec{V} \overline{f^{\prime 2}}\right)=\nabla \cdot\left(\frac{\mu_{t}}{\sigma_{t}} \nabla \overline{f^{\prime 2}}\right)+C_{g} \mu_{t}(\nabla \bar{f})^{2} \\
-C_{d} \rho \frac{\varepsilon}{k} \overline{f^{\prime 2}}+S_{\text {user }},
\end{gathered}
$$

where $\bar{f}$ is the mixture fraction, $\overline{f^{\prime 2}}$ is the mixture fraction variance, and the constant values of $\sigma_{t}, C_{g}$, and $C_{d}$ are 0.85 , 2.86 , and 2.0 , respectively.

\section{Model Validation}

In order to validate the numerical model, the experiment and numerical simulation have been carried out for the original oil combustor. The boundary conditions of the experimental and numerical cases are as follows: the air mass flow rate is $1.19 \mathrm{~kg} / \mathrm{s}$, the temperature is $758.6 \mathrm{~K}$, the pressure is 0.573 $\mathrm{MPa}$, the oil mass flow rate is $0.0264 \mathrm{~kg} / \mathrm{s}$, and the temperature is $300 \mathrm{~K}$. The combustor outlet temperature was measured by twenty thermocouples, which were arranged uniformly at the combustor outlet. In the experiment, the 


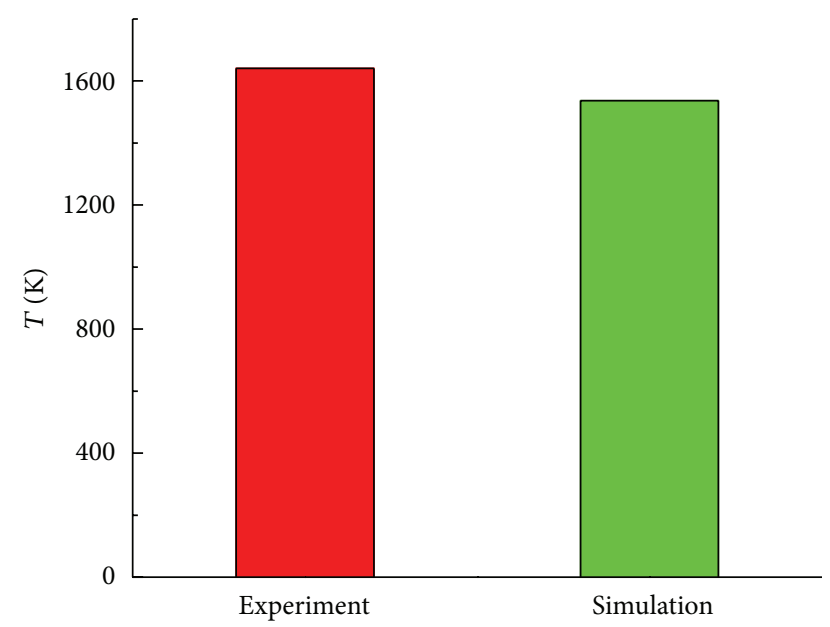

FIGURE 4: Combustor outlet average temperature: comparison between experimental and simulation results.

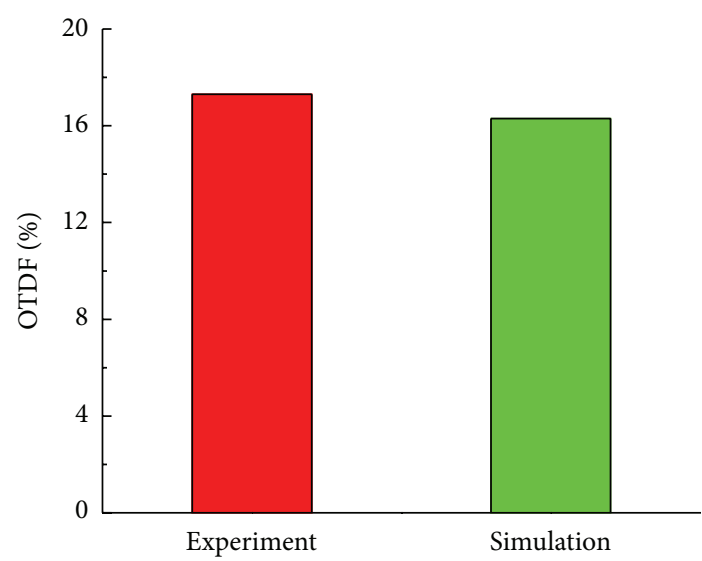

FIGURE 5: OTDF of combustor: comparison between experimental and simulation results.

combustor outlet temperature was measured three times, and the final experimental data was the average of three measurements.

The combustor outlet average temperatures have been obtained through both experimental investigation and numerical simulation, as seen in Figure 4. The temperature of simulation result is a little lower than that of the experimental result, but the relative error between the simulation and experimental results is only $6.3 \%$. This confirms the reasonable accuracy of the numerical model adopted in the present paper. To further validate the suitability of the numerical model, the OTDF (overall temperature distribution factor), and RTDF (radial temperature distribution factor) of combustor have also been studied. As shown in Figure 5, the experimental and simulation values of OTDF are $17.3 \%$ and $16.3 \%$, respectively. And the RTDF are $7.4 \%$ and $6.7 \%$ respectively, as seen in Figure 6. Figures 5 and 6 reveal that the numerical results operated in the present study fit satisfactorily with experimental data. Thus, the numerical model used in this paper is reliable and applicable for the solution of combustion flow field in combustor.

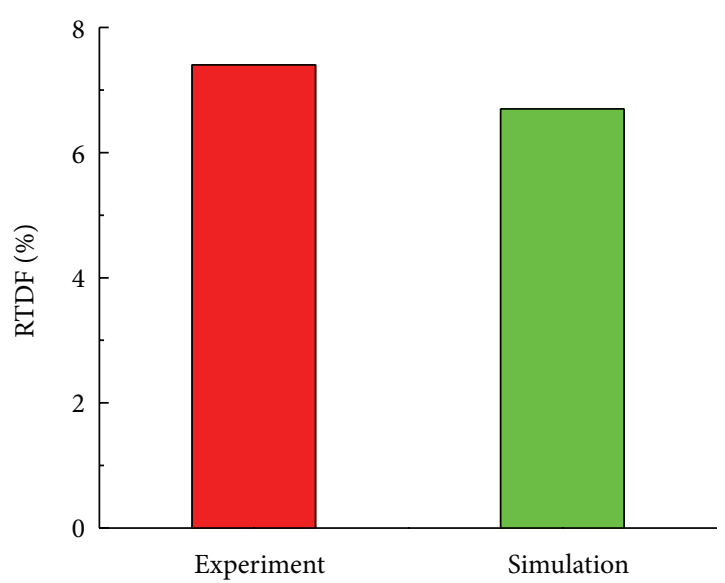

FIGURE 6: RTDF of combustor: comparison between experimental and simulation results.

\section{Results and Discussion}

4.1. Flow Field Analysis. Studying the streamlines of velocity field in the combustor provides a better understanding of the effect of the dual fuel nozzle structure on the flow patterns. Figure 7 shows the streamlines of velocity field within the combustor under reactive situation for different dual fuel nozzle structures. As can be seen from the figures, the dual fuel nozzle structure has little effect on the flow field out of the combustor liner, but a significant effect on the flow field in the combustor liner. In the inner swirl nozzle combustor, the fuel flows directly to the combustor outlet, and some small vortexes form in the primary zone of the combustor. However, in the outer swirl nozzle or double swirl nozzle combustor, there is a counter-rotating vortex pair forming in the primary zone of the combustor, which is the main characteristic of the CRZ. The CRZ can provide the heat source by upstream convection and mixing of hot reaction products with a fresh charge of fuel and air, and reduce the mixture velocity to be in the range of flame speed which is necessary for flame stabilization.

The conclusion can be made that the nozzle with a swirler in the outer channel can obtain a better flow field. The reason is that the fuel flowing through the outer swirler can obtain a swirling velocity and then mix with the swirling air from the combustor swirler. After that, the swirling mixture of fuel and air flows forward and entraps the air in the center area of the combustor, and at the same time, the downstream air refills the region, then the CRZ is formed. However, in the inner swirl nozzle combustor, though the fuel flowing through the inner swirler can also obtain a swirling velocity, the axial direction velocity of the fuel flowing through the outer channel can offset the swirl effect of the fuel from the inner swiler, so the fuel flows directly to the combustor outlet finally. And due to the effect of the swirling air, there are some small vortexes in the primary zone. Therefore, the fuel concentration field and combustion field would be better in the outer swirl nozzle combustor and double swirl nozzle combustor than that in inner swirl nozzle combustor. 


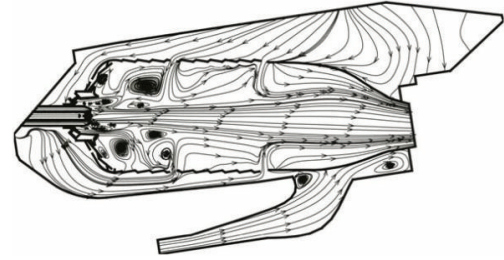

(a) Inner swirl nozzle

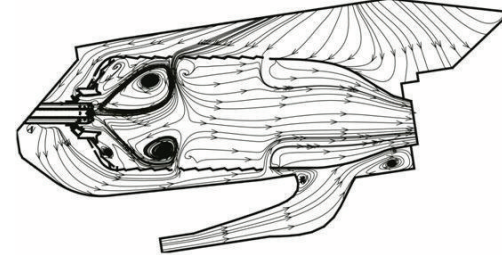

(b) Double swirl nozzle

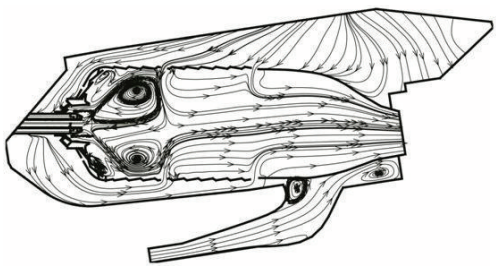

(c) Outer swirl nozzle

FIGURE 7: Streamlines of velocity field for different dual fuel nozzle structures.

4.2. Fuel Concentration Distribution Analysis. Fuel injection and mixing are critical to achieving efficient and clean combustion in modern gas turbine combustors. The fuel concentration distribution analysis is an effective method to research the fuel injection and mixing in the combustor. In this paper, fuel concentration distribution within the combustor under a steady reactive condition for the three dual fuel nozzles was investigated numerically. The components of $\mathrm{H}_{2}$ and $\mathrm{CO}$ were selected to investigate the fuel concentration distribution in the combustor because they were the combustible components in the fuel. The profiles of $\mathrm{H}_{2}$ and $\mathrm{CO}$ mole fraction in the combustor middle plane are shown in Figures 8 and 9, respectively. In these figures, $x$ represents the position of the $X$-axis. The profiles of $\mathrm{H}_{2}$ and $\mathrm{CO}$ mole fraction show the radial spread of fuel jets, progress of fuel-air mixing, and fuel combustion. As can be seen in Figure 8, the $\mathrm{H}_{2}$ mole fraction profiles for the three nozzles have different shapes. In the inner swirl nozzle combustor, at $x=110 \mathrm{~mm}$, the profile of $\mathrm{H}_{2}$ is a cone with its apex on the axis, which does not change at $x=210 \mathrm{~mm}$, suggesting that the mixing of air and fuel in the combustor is far from complete. The peak values of the $\mathrm{H}_{2}$ mole fraction are 0.40208 at $x=110$ and 0.3573 at $x=210$, respectively, suggesting that the combustion of fuel is far from complete.

In the double swirl nozzle combustor, at $x=110 \mathrm{~mm}$, the profile of $\mathrm{H}_{2}$ has two peaks and shows an $\mathrm{M}$ shape. The $\mathrm{H}_{2}$ mole fraction decreases with increasing the axial distance, due to mixing with air and the combustion of fuel. And the radial space of the $\mathrm{H}_{2}$ distribution becomes wider with increasing the axial distance, due to the swirling flow of the fuel. More uniform profiles of $\mathrm{H}_{2}$ mole fraction are observed further downstream (i.e., $x=190$ and $210 \mathrm{~mm}$ ). And the values of $\mathrm{H}_{2}$ mole fraction are nearly zero, illustrating that the combustion of fuel almost completes. It can also be seen from Figure 8, due to the swirling effect of the double swirl nozzle, that more fuel is injected away from the central axis of the combustor liner, so the $\mathrm{H}_{2}$ mole fraction is almost zero in the center area of the combustor.

In the outer swirl nozzle combustor, the M-shaped $\mathrm{H}_{2}$ mole fraction profiles are also presented. With increasing axial distance, due to the mixing with air and the combustion of fuel, the two peaks are diminished at $x=210 \mathrm{~mm}$. The value of the $\mathrm{H}_{2}$ mole fraction is nearly zero at $x=210 \mathrm{~mm}$ illustrating that the combustion of fuel almost completes. And the radial space of the $\mathrm{H}_{2}$ distribution in this combustor is almost the same with the double swirl nozzle combustor. Different from the double swirl nozzle combustor, the $\mathrm{H}_{2}$ mole fraction just downstream of the outer swirl nozzle is not zero in the center area of this combustor. This illustrates that the fuel distribution space is broader in the outer swirl nozzle combustor than that in double swirl nozzle combustor.

As shown in Figure 9, the variation of the CO mole fraction profiles with axial distance is generally consistent with that of $\mathrm{H}_{2}$ mole fraction profiles. Cone shape for the inner swirl nozzle combustor and $\mathrm{M}$ shape for the other two nozzle combustors of CO mole fraction profiles are observed. It can also be seen from Figure 9 that the decreases of the CO mole fraction with increasing axial distance are not as significantly the same as the $\mathrm{H}_{2}$ mole fraction. The reason is that the burning speed of $\mathrm{H}_{2}$ is faster than that of $\mathrm{CO}$.

A comparison of the fuel concentration profiles shows that the double swirl nozzle and outer swirl nozzle can inject the fuel into a broader space than the inner swirl nozzle. So the fuel can be mixed with air rapidly in the double swirl nozzle combustor and outer swirl nozzle combustor. The distance of the complete fuel combustion is shorter in the double swirl nozzle combustor and outer swirl nozzle combustor than in the inner swirl nozzle combustor.

4.3. Temperature Distribution Analysis. The temperature distributions within the combustor under a steady reactive condition for the three nozzles are compared in Figure 10. In the inner swirl nozzle combustor, the high temperature region is mainly located in the dilution zone. It is because the fuel is not mixed rapidly and well with the air. In the double swirl nozzle combustor, the high temperature region is mainly located in the primary zone, but near the combustor liner. It is because there is little fuel in the center area of the combustor, so the fuel is burned near the combustor liner. This would cause a high combustor liner metal temperature and then shorten the service life of the combustor liner. In the outer swirl nozzle combustor, the high temperature region is mainly located in the CRZ, which is useful to stabilize the flame. The combustion flow field in this combustor is better compared to that of the former two combustors.

Figure 11 shows temperature profiles along the central axis in the combustor liner for the three nozzles. As can be seen from the figure, the trends of the temperature profiles are different for the three nozzles. For the fuel that is not mixed well with the air in the primary zone, the highest temperature on the central axis in the inner swirl nozzle combustor is near the combustor outlet. Because the fuel is burned near the combustor liner, the highest temperature on the central axis 


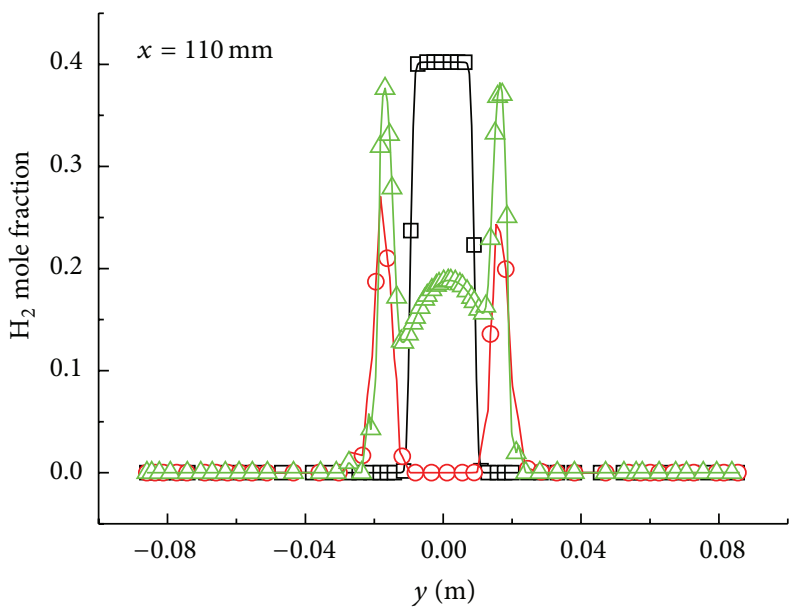

(a)

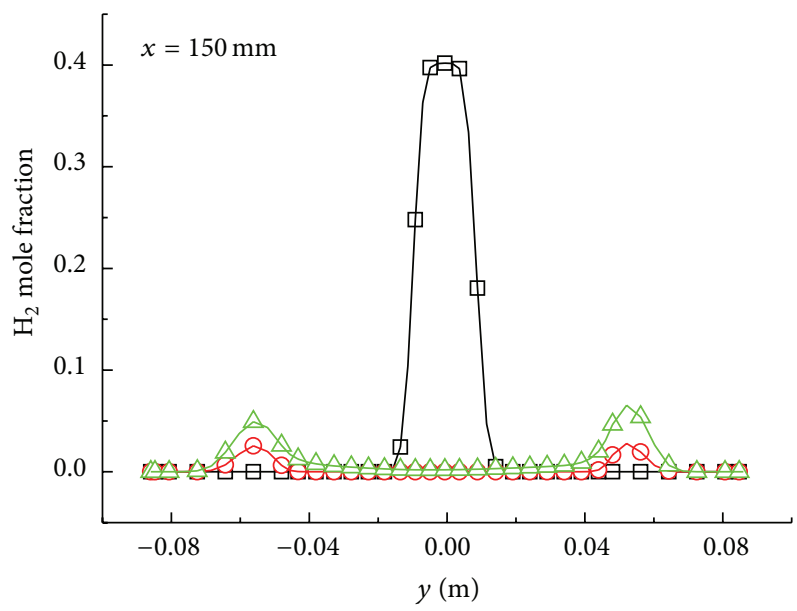

(c)

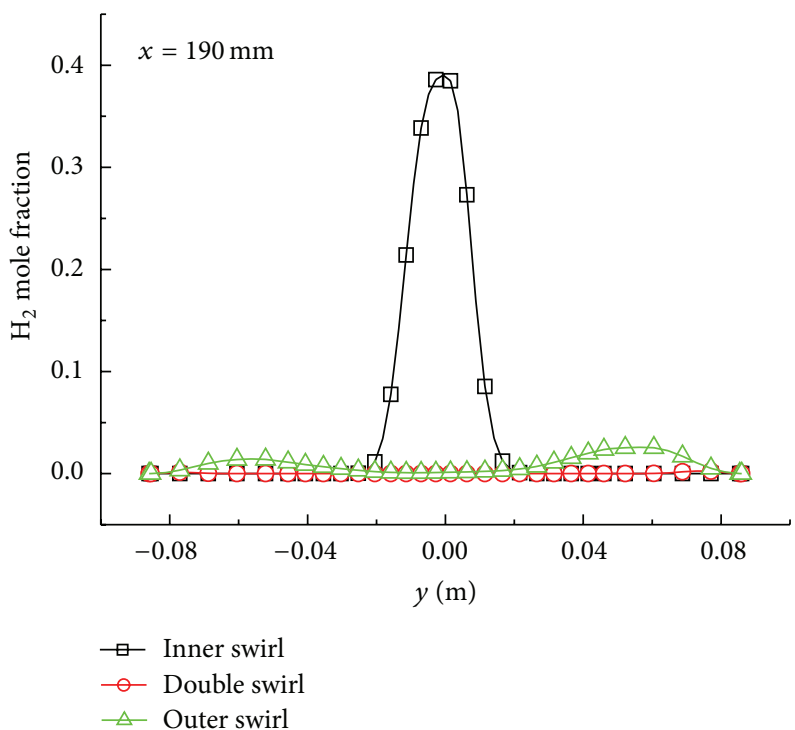

(e)

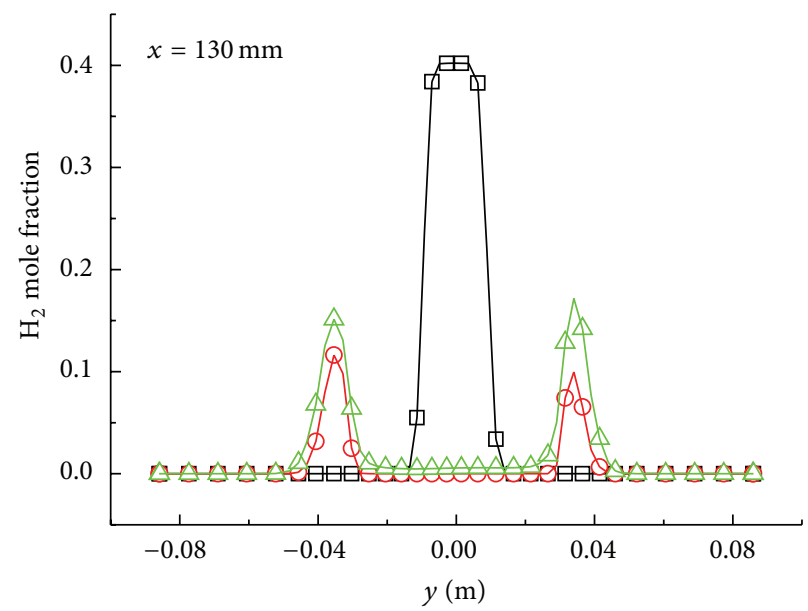

(b)

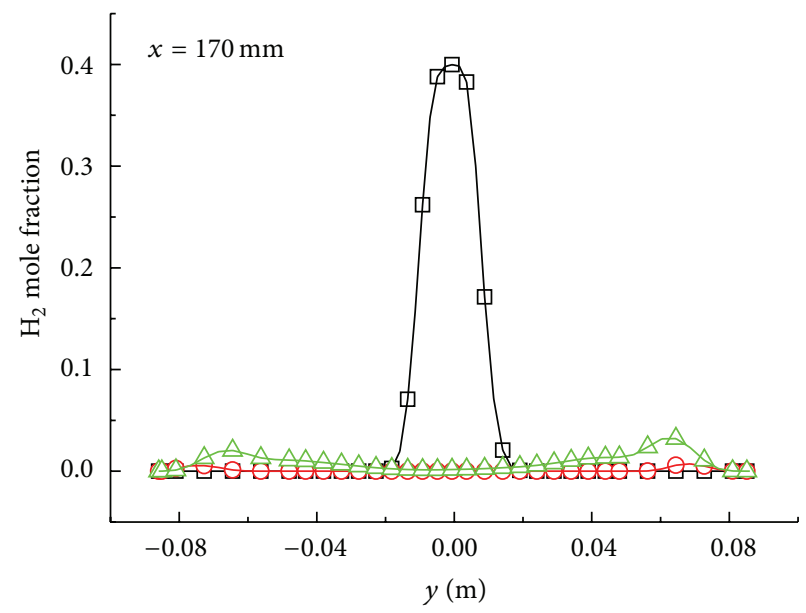

(d)

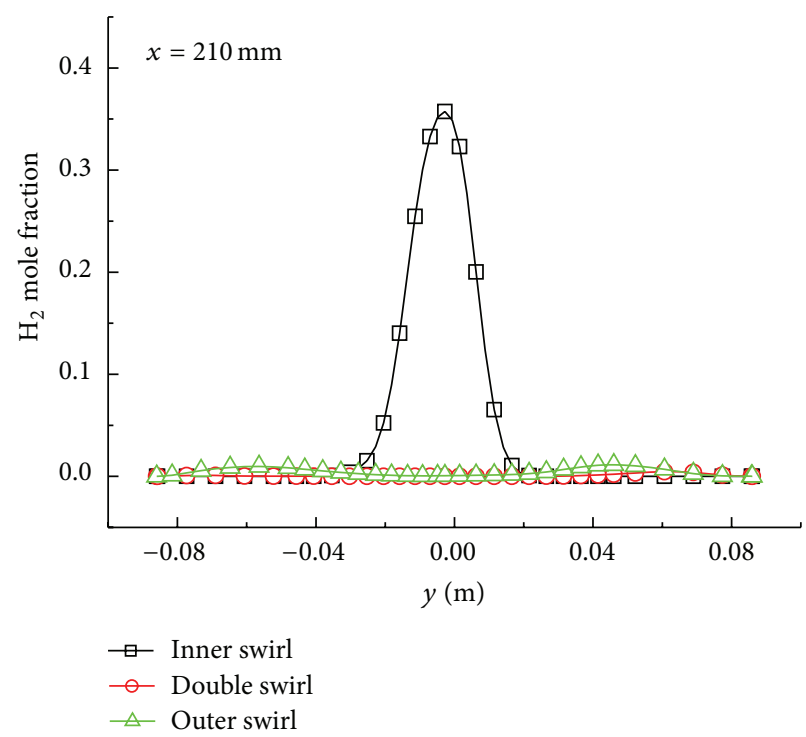

(f)

Figure 8: Profiles of $\mathrm{H}_{2}$ mole fraction in the combustor middle plane. 


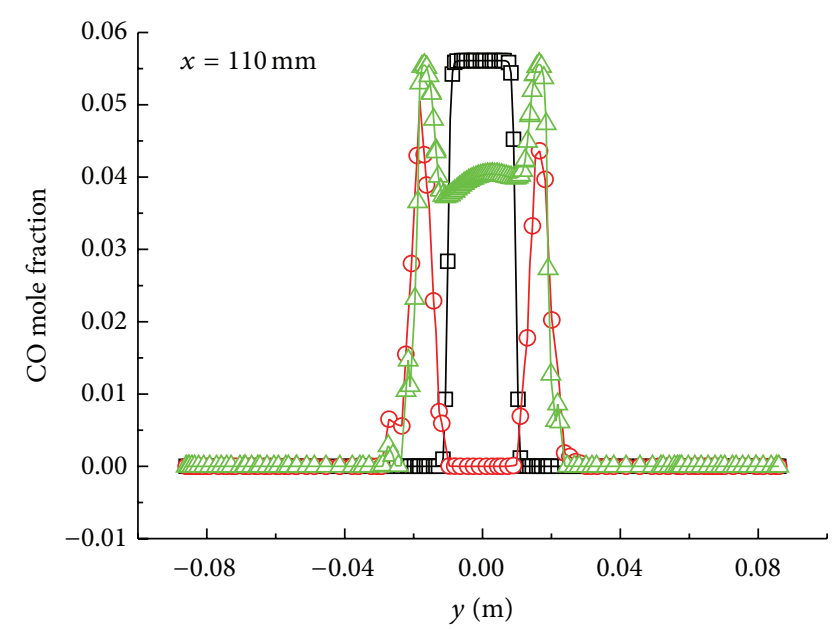

(a)

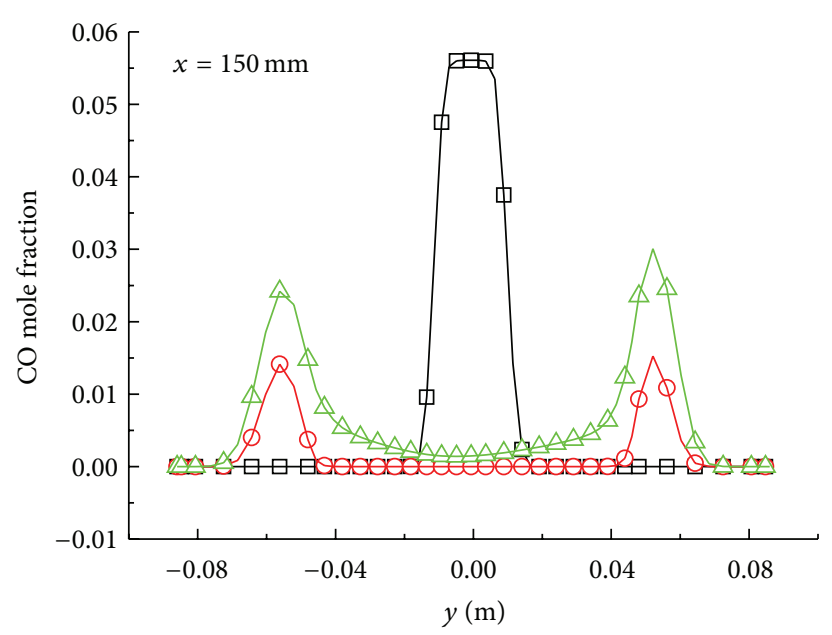

(c)

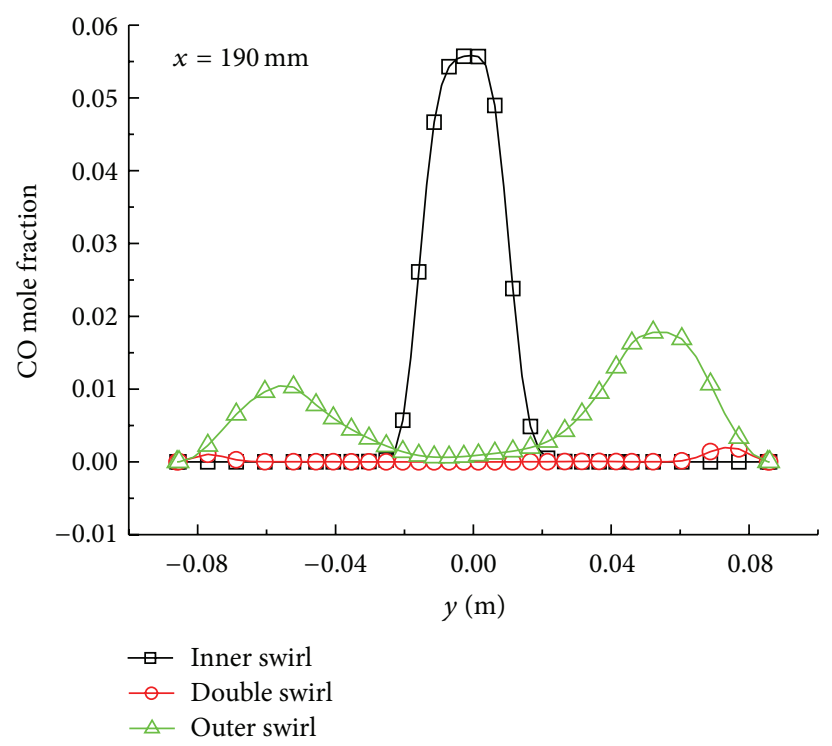

(e)

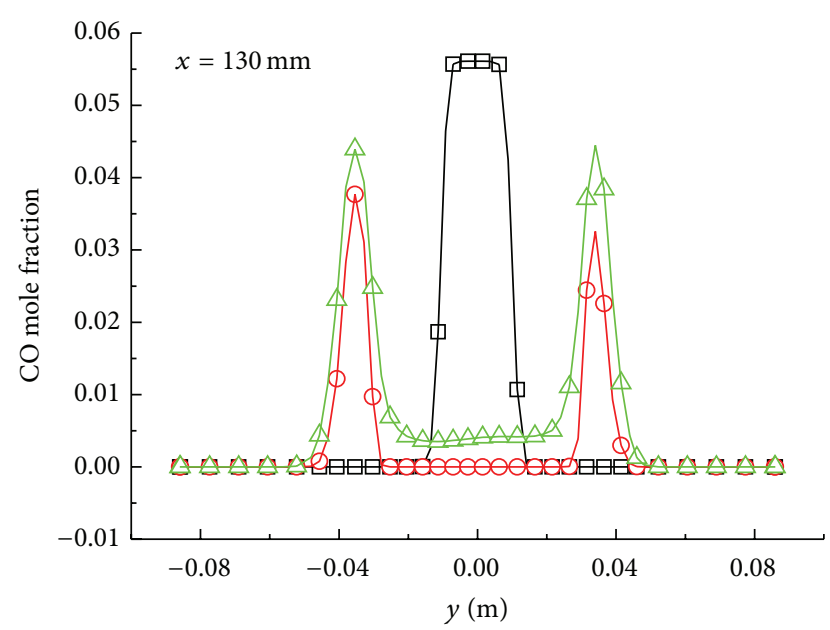

(b)

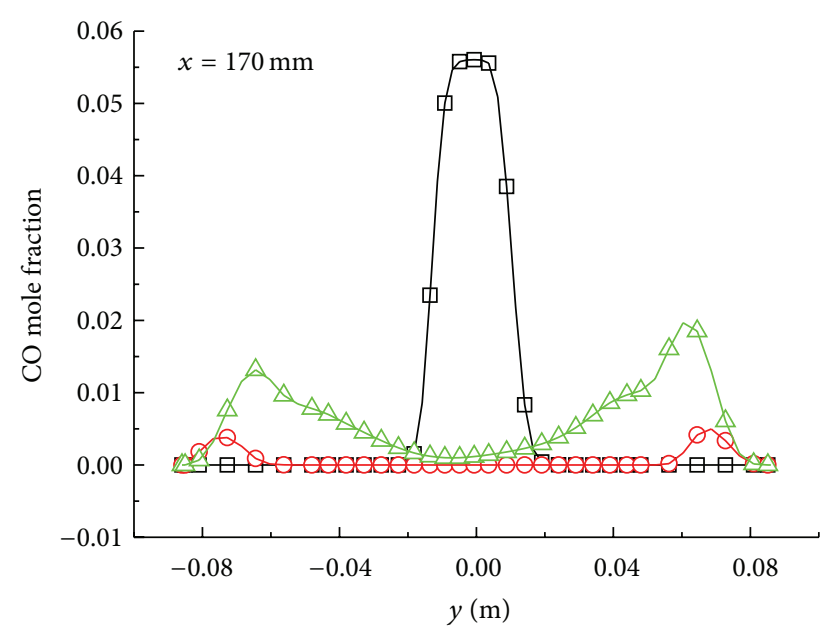

(d)

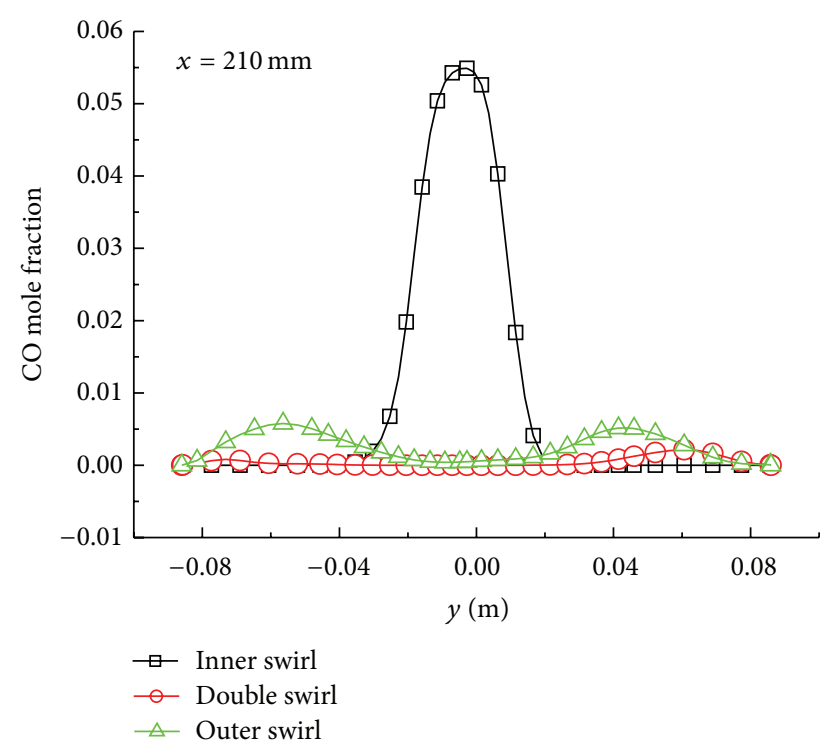

(f)

FIgURE 9: Profiles of $\mathrm{CO}$ mole fraction in the combustor middle plane. 

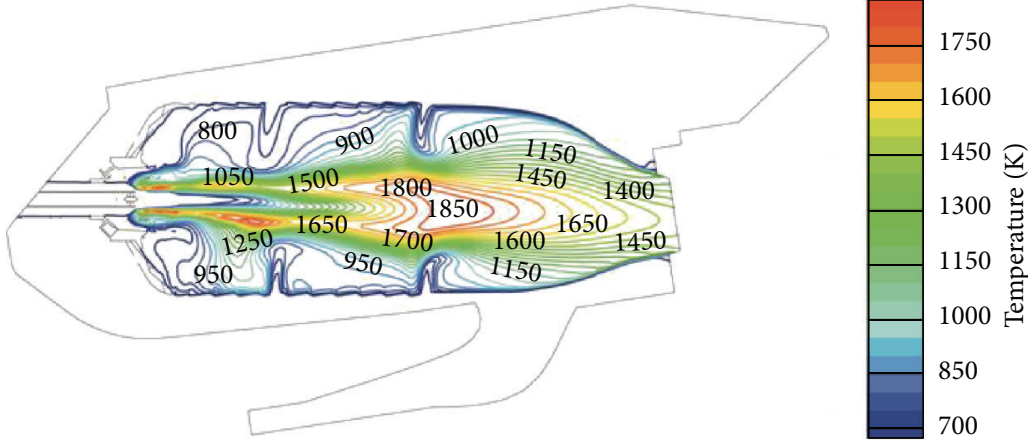

(a) Inner swirl nozzle

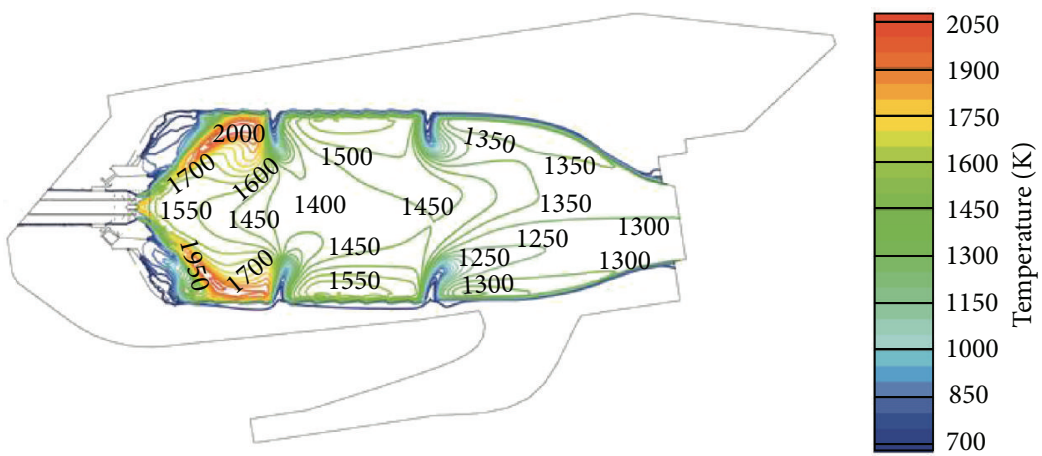

(b) Double swirl nozzle

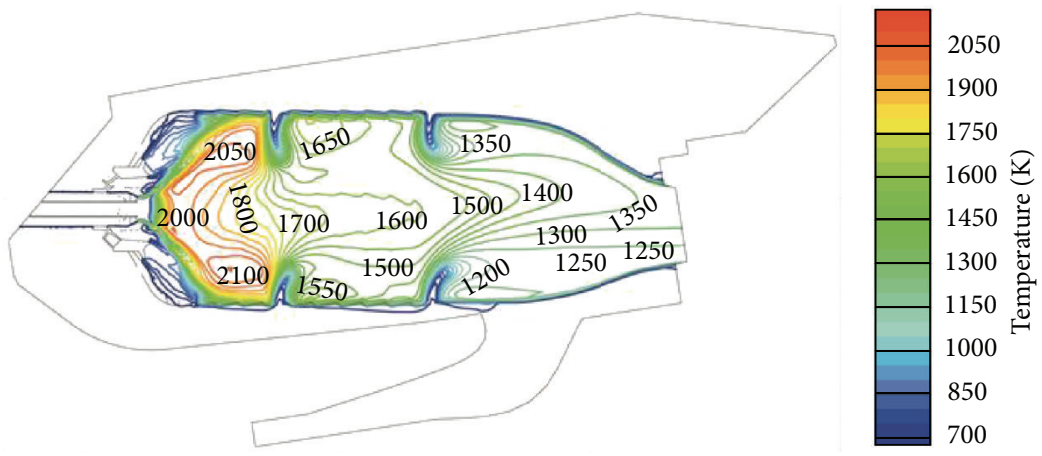

(c) Outer swirl nozzle

FIGURE 10: Temperature distributions in the combustor.

in the double swirl nozzle combustor is lower than that of the other two combustors. In the outer swirl nozzle combustor, due to the better combustion flow field, the highest temperature on the central axis is in the CRZ.

The combustor outlet temperature distribution and the corresponding pattern factor have a strong impact on a gas turbine plant. Figure 12 shows the outlet temperature distributions of different nozzle structures. It is observed under all situations that the outlet temperature distributions are not the same. In the inner swirl nozzle combustor, the maximum value of outlet temperature is almost at the center position of the combustor outlet, which is $1500 \mathrm{~K}$. In the double swirl nozzle combustor, the maximum value of outlet temperature is located in the upper right of the combustor outlet, which is $1340 \mathrm{~K}$. In the outer swirl nozzle combustor, the position of the maximum outlet temperature is almost the same with the double swirl nozzle combustor and the maximum temperature value is $1350 \mathrm{~K}$.
Figures 13-15 show the OTDF (overall temperature distribution factor), RTDF (radial temperature distribution factor) and CTDF (circumferential temperature distribution factor) of combustor, respectively. The OTDF, RTDF and CTDF are defined respectively as follows:

$$
\begin{aligned}
& \mathrm{OTDF}=\frac{T_{t 4 \max }-T_{t 4}}{T_{t 4}-T_{t 3}} \times 100 \%, \\
& \mathrm{RTDF}=\frac{T_{t 4 r \max }-T_{t 4}}{T_{t 4}-T_{t 3}} \times 100 \%, \\
& \mathrm{CTDF}=\frac{T_{t 4 c \max }-T_{t 4}}{T_{t 4}-T_{t 3}} \times 100 \%,
\end{aligned}
$$

where $T_{t 4 \max }$ is combustor outlet maximum temperature, $T_{t 4 r \max }$ is combustor outlet radial maximum temperature, 


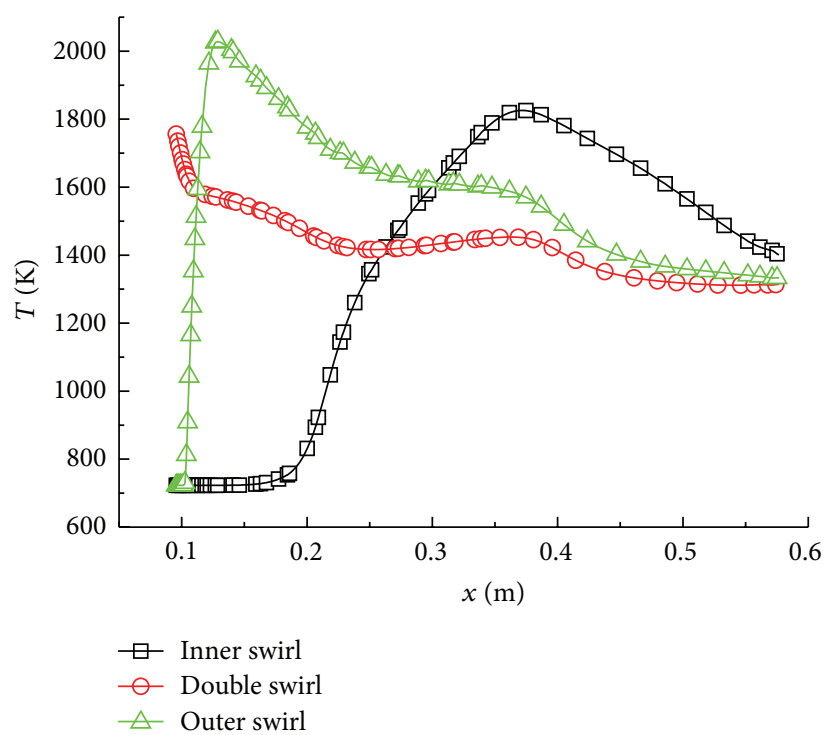

FIGURE 11: Temperature profiles along the central axis.

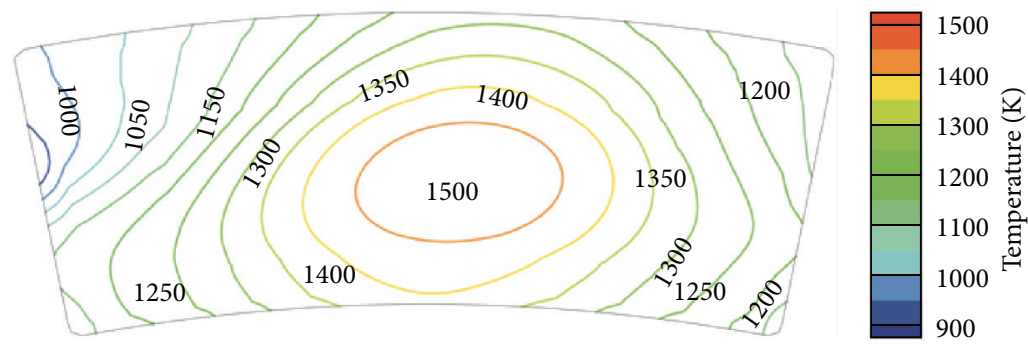

(a) Inner swirl nozzle

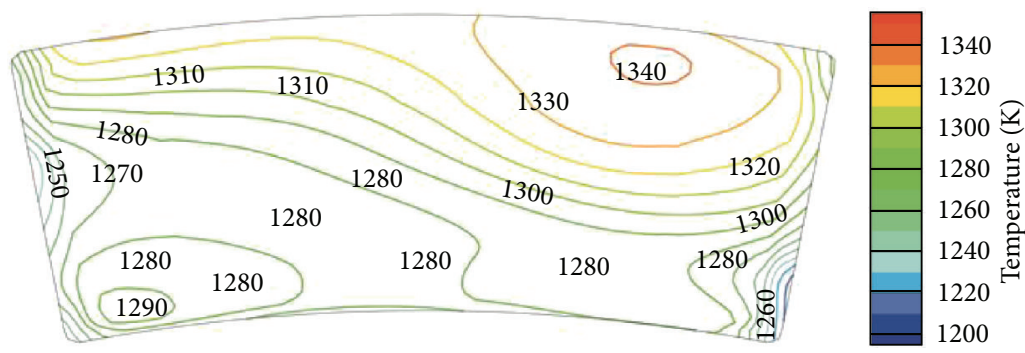

(b) Double swirl nozzle

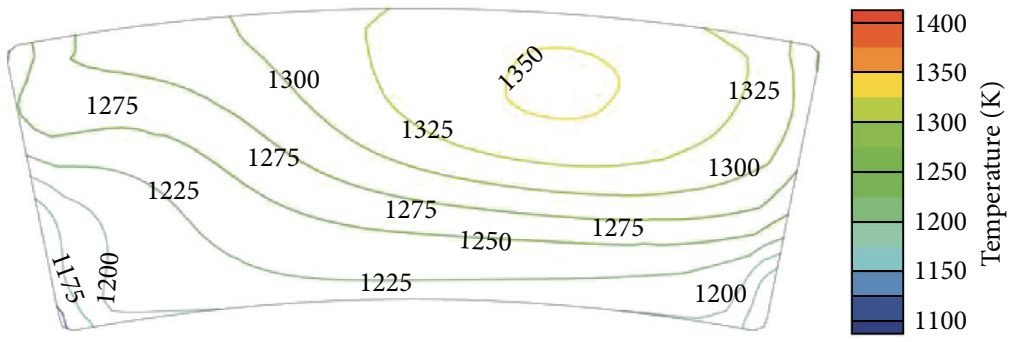

(c) Outer swirl nozzle

FIgURE 12: Combustor outlet temperature distribution. 


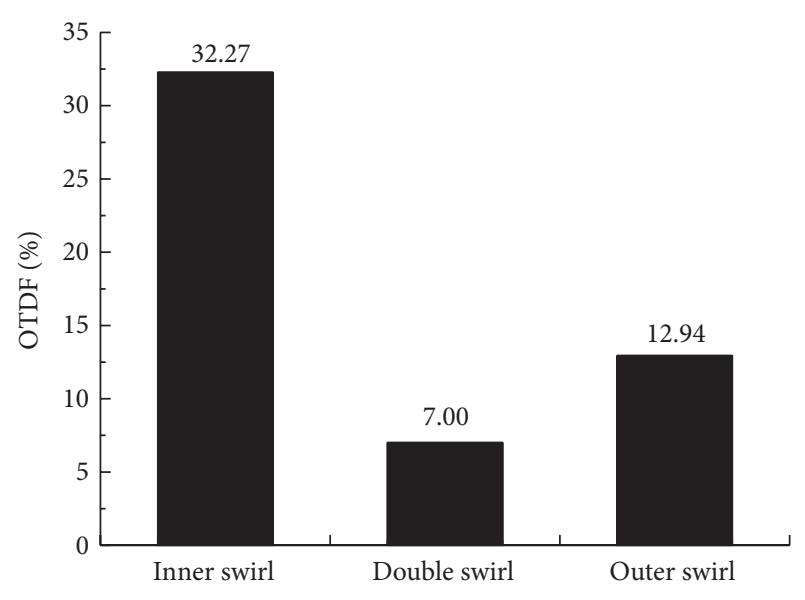

FIGURE 13: OTDF of combustor.

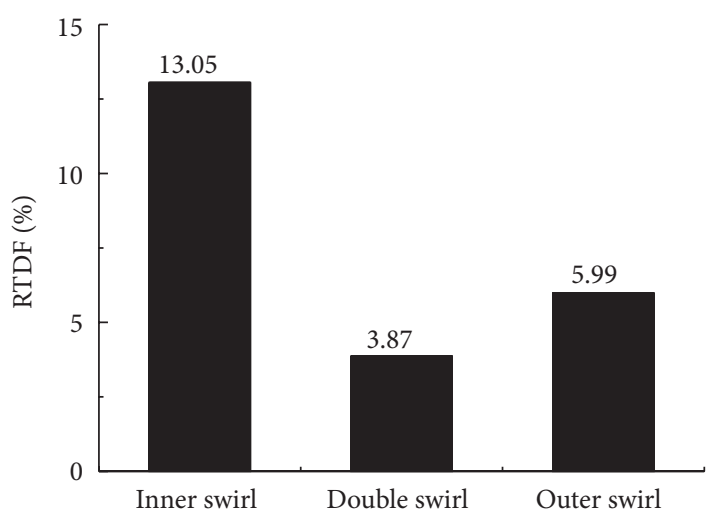

FIGURE 14: RTDF of combustor.

$T_{t 4 c \max }$ is combustor outlet circumferential maximum temperature, $T_{t 4}$ is combustor outlet average temperature, and $T_{t 3}$ is air inlet temperature.

The combustor design requires OTDF to be less than $30 \% \sim 35 \%$. As can be seen from Figure 13, the OTDF of the inner swirl nozzle combustor is $32.27 \%$, which is higher than $30 \%$ and does not meet the requirement fully. However, the OTDF of the double and outer swirl nozzle combustors satisfy the requirement, which are $7 \%$ and $12.94 \%$, respectively.

The combustor design requires RTDF and CTDF to be less than 10\%. As can be seen from Figures 14 and 15, the RTDF and CTDF of the inner swirl nozzle combustor are higher than $10 \%$. The double swirl nozzle combustor has the smallest RTDF and CTDF which are $3.87 \%$ and $1.85 \%$, respectively. Though the RTDF and CTDF of the outer swirl nozzle combustor are larger than the double swirl nozzle combustor, they are still less than $10 \%$. The conclusion can be made that the double swirl nozzle combustor outlet temperature distribution is the best, followed by the outer swirl nozzle combustor and the worst is the inner swirl nozzle combustor.

The results of the study as discussed above provide the guideline to decide upon the different dual fuel nozzle structures to have the desired performances. In summary, the combustor with the outer swirl nozzle can obtain a better combustion flow field. So this nozzle is selected for the CRGT system finally.

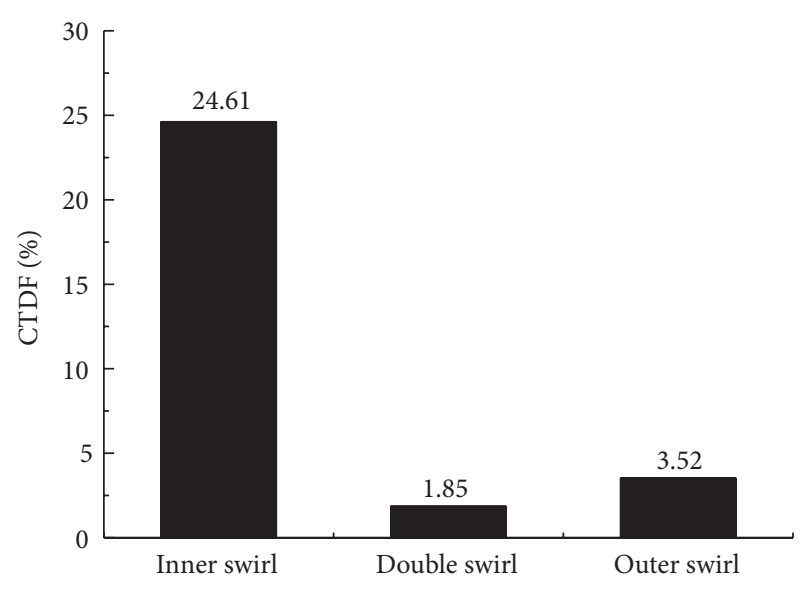

FIGURE 15: CTDF of combustor.

\section{Conclusion}

In this paper, in order to burn reformed gas effectively, three different structures of a new dual fuel nozzle design concept (inner swirl nozzle, double swirl nozzle, and outer swirl nozzle) were developed. And the combustion flow field in the combustor with the nozzles was investigated, respectively. The realizable $k-\varepsilon$ model was used for turbulence modeling, PDF model for nonpremixed gas combustion. The effects of the different dual fuel nozzle structures on the flow field, fuel concentration distribution, and temperature distribution in the combustor were simulated and analyzed. The conclusions are as follows.

(1) Due to the swiler in the outer channel of the nozzle, the double swirl nozzle and outer swirl nozzle combustor can get a better flow filed with an obvious CRZ.

(2) The fuel concentration distribution presents a cone shape in the inner swirl nozzle combustor and an M shape in the double swirl nozzle combustor and outer swirl nozzle combustor. The profile of fuel concentration distribution in the upstream region in the combustor for the double swirl nozzle and outer swirl nozzle is more uniform than that for inner swirl nozzle. The mixing of fuel and air is more rapid in the double swirl nozzle and outer swirl nozzle combustors than in the inner swirl nozzle combustor, which results in shorter distance of complete fuel combustion in the combustor.

(3) The high temperature region is near the combustor outlet for the inner swirl nozzle and the outlet temperature distribution factors do not meet the requirement fully. The outlet temperature distribution factors for the double swirl nozzle meet the requirement fully, but the high temperature region is near the combustor liner which can shorten the service life of the liner. In the outer swirl nozzle combustor, the high temperature region is mainly located in the CRZ and the outlet temperature distribution factors also satisfy the requirement fully. 
The results obtained in this study show the differences in flow field, fuel concentration distribution, and temperature distribution when the combustor is equipped with the three dual fuel nozzles, respectively. The results illustrate that the combustor with the outer swirl nozzle has a better combustion flow field.

\section{References}

[1] G. L. Juste, "Hydrogen injection as additional fuel in gas turbine combustor. Evaluation of effects," International Journal of Hydrogen Energy, vol. 31, no. 14, pp. 2112-2121, 2006.

[2] T. Nakagaki, T. Ogawa, H. Hirata, K. Kawamoto, Y. Ohashi, and K. Tanaka, "Development of chemically recuperated micro gas turbine," Journal of Engineering for Gas Turbines and Power, vol. 125, no. 1, pp. 391-397, 2003.

[3] K. F. Kesser, M. A. Hoffman, and J. W. Baughn, "Analysis of a basic chemically recuperated gas turbine power plant," Journal of Engineering for Gas Turbines and Power, vol. 116, no. 2, pp. 277-284, 1994.

[4] T. Terasaki and S. Hayashi, "The effects of fuel-air mixing on NOx formation in non-premixed swirl burners," in Proceedings of the 26th Symposium International on Combustion, pp. 27332739, The Combustion Institute, 1996.

[5] C. O. Iyogun, M. Birouk, and J. A. Kozinski, "Experimental investigation of the effect of fuel nozzle geometry on the stability of a swirling non-premixed methane flame," Fuel, vol. 90, no. 4, pp. 1416-1423, 2011.

[6] H. B. Li, H. S. Zhen, C. W. Leung, and C. S. Cheung, "Nozzle effect on heat transfer and $\mathrm{CO}$ emission of impinging premixed flames," International Journal of Heat and Mass Transfer, vol. 54, no. 1-3, pp. 625-635, 2011.

[7] H. S. Zhen, Y. S. Choy, C. W. Leung, and C. S. Cheung, "Effects of nozzle length on flame and emission behaviors of multi-fuel-jet inverse diffusion flame burner," Applied Energy, vol. 88, no. 9, pp. 2917-2924, 2011.

[8] M. C. Lee and Y. Yoon, "Development of a gas turbine fuel nozzle for DME and a design method thereof," Fuel, vol. 102, pp. 823-830, 2012.

[9] M. S. Mansour, A. M. Elbaz, and M. Samy, "The stabilization mechanism of highly stabilized partially premixed flames in a concentric flow conical nozzle burner," Experimental Thermal and Fluid Science, vol. 43, pp. 55-62, 2012.

[10] M. Koyama and S. Tachibana, "Technical applicability of lowswirl fuel nozzle for liquid-fueled industrial gas turbine combustor," Fuel, vol. 107, pp. 766-776, 2013.

[11] O. Liedtke and A. Schulz, "Development of a new lean burning combustor with fuel film evaporation for a micro gas turbine," Experimental Thermal and Fluid Science, vol. 27, no. 4, pp. 363369, 2003.

[12] E. H. Chui, A. J. Majeski, M. A. Douglas, Y. Tan, and K. V. Thambimuthu, "Numerical investigation of oxy-coal combustion to evaluate burner and combustor design concepts," Energy, vol. 29, no. 9-10, pp. 1285-1296, 2004.

[13] M. Koyama and H. Fujiwara, "Development of a dual-fuel gas turbine engine of liquid and low-calorific gas," JSME International Journal B, vol. 49, no. 2, pp. 224-229, 2006.

[14] K. A. Al-attab and Z. A. Zainal, "Design and performance of a pressurized cyclone combustor (PCC) for high and low heating value gas combustion," Applied Energy, vol. 88, no. 4, pp. 10841095, 2011.
[15] V. K. Arghode and A. K. Gupta, "Development of high intensity CDC combustor for gas turbine engines," Applied Energy, vol. 88, no. 3, pp. 963-973, 2011.

[16] F. Xing, P. Wang, S. Zhang et al., "Experiment and simulation study on lean blow-out of trapped vortex combustor with various aspect ratios," Aerospace Science and Technology, vol. 18, no. 1, pp. 48-55, 2012.

[17] M. Graça, A. Duarte, P. J. Coelho, and M. Costa, "Numerical simulation of a reversed flow small-scale combustor," Fuel Processing Technology, vol. 107, pp. 126-137, 2013.

[18] C. Ghenai, "Combustion of syngas fuel in gas turbine can combustor," Advances in Mechanical Engineering, vol. 2010, Article ID 342357, 13 pages, 2010.

[19] ANSYS Fluent 12.0 Theory Guide. 


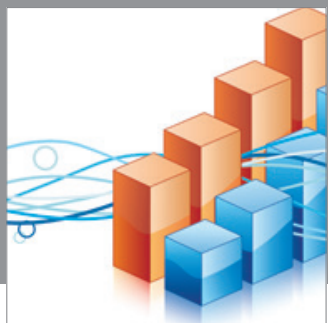

Advances in

Operations Research

mansans

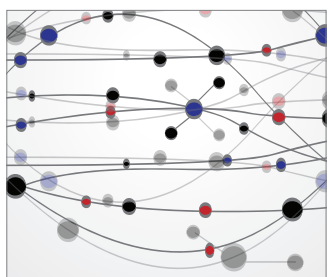

The Scientific World Journal
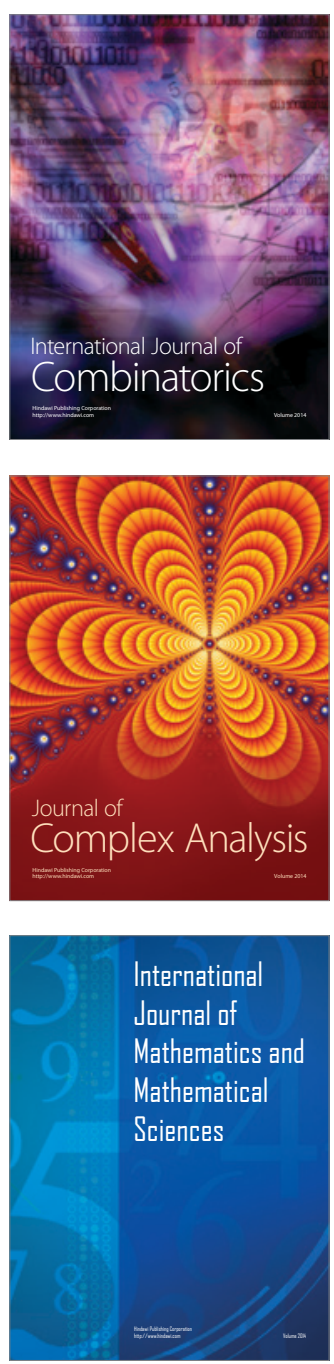
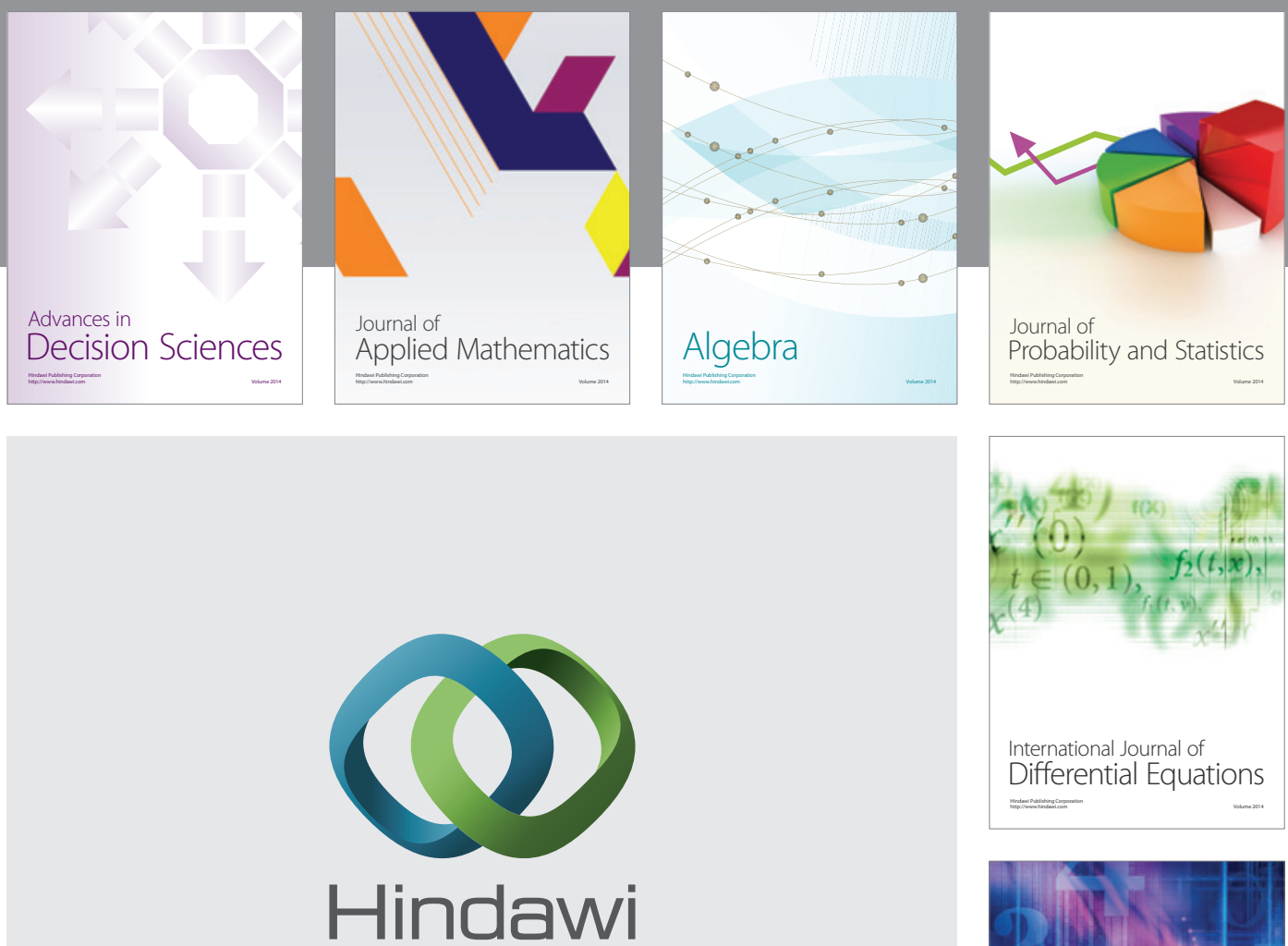

Submit your manuscripts at http://www.hindawi.com
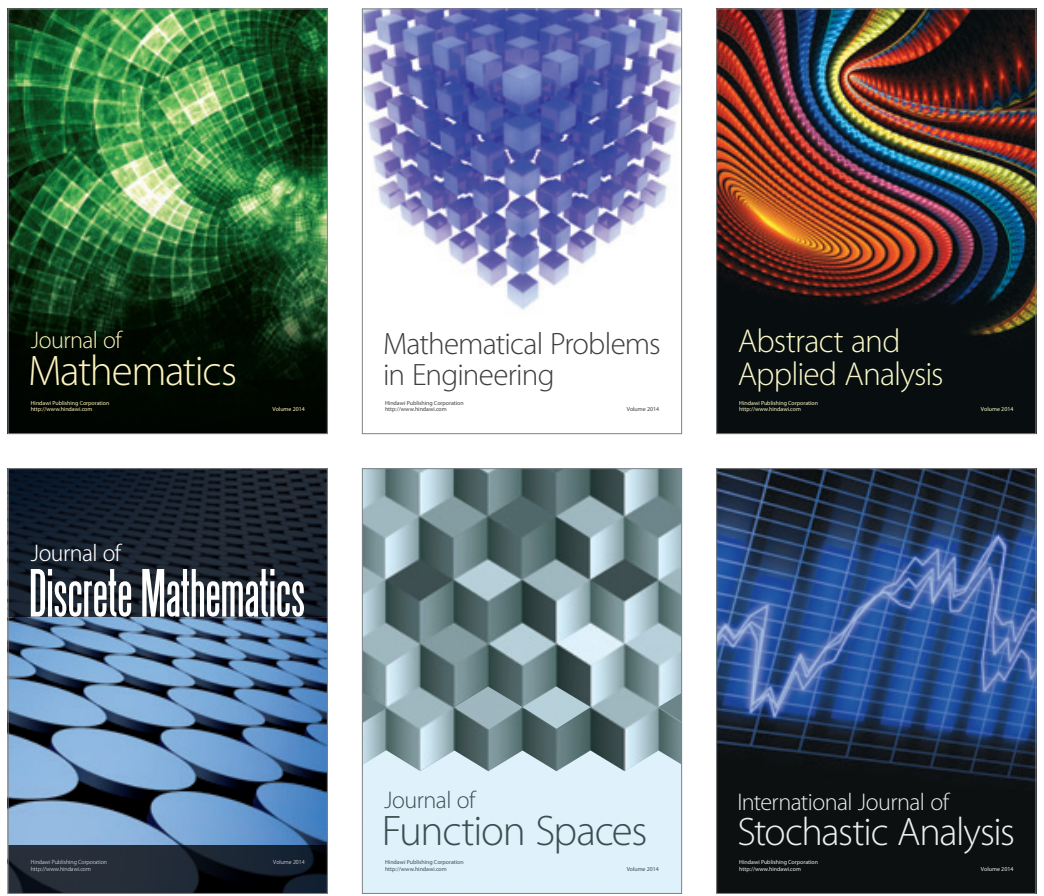

Journal of

Function Spaces

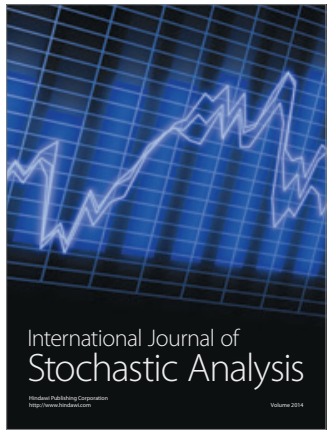

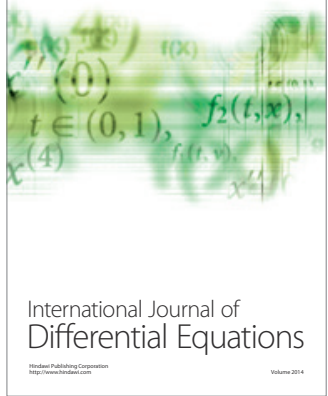
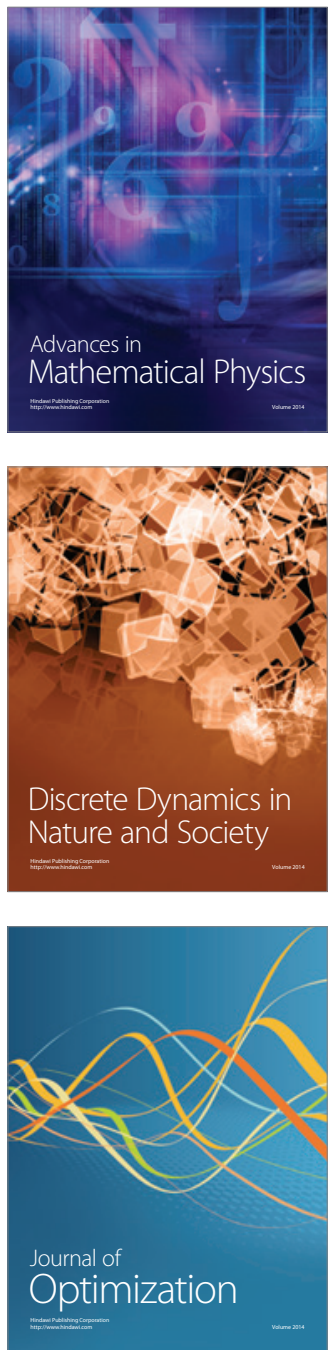